\title{
An Observer Tool for to Enhance Learning of Anesthesia Resident's Non-Technical Skills During High-Fidelity Simulation: A Randomized Controlled Trial
}

\section{Antonia Blanié ( $\nabla$ antonia.blanie@aphp.fr)}

Centre de simulation LabForSIMS de la Faculté de Médecine Paris -Saclay, Université Paris-Saclay CIAMS, CIAMS, Université d'Orléans

\section{Gauthier-Charles Arcile}

Centre de simulation LabForSIMS de la Faculté de Médecine Paris -Saclay, Université Paris-Saclay CIAMS, CIAMS, Université d'Orléans

\section{Philippe Roulleau}

CHU Bicêtre, Groupe hospitalo-universitaire Paris Saclay

\section{Dan Benhamou}

Centre de simulation LabForSIMS de la Faculté de Médecine Paris -Saclay, Université Paris-Saclay CIAMS, CIAMS, Université d'Orléans

\section{Research Article}

Keywords: simulation, anesthesia; non-technical skills; observer tool; observational learning

Posted Date: September 14th, 2021

DOI: https://doi.org/10.21203/rs.3.rs-819455/v1

License: (c) (i) This work is licensed under a Creative Commons Attribution 4.0 International License. Read Full License 


\section{Abstract}

Background: An observer tool (OT) dedicated to technical skills could improve learning of medical knowledge during simulation. However, it remains uncertain whether non-technical skills learning outcomes might be improved by using an OT.

Methods: After consent, anesthesia residents enrolled to a crisis management training simulation were randomized to use an observer tool (OT +) (based on non-technical skills) or not (OT-) when not roleplaying. The main outcome parameter was non-technical skills learning outcomes assessed by the global score of non-technical skills learning after the training (self-assessment using the 15 items of 4 categories of the Anaesthetists' Non-Technical Skills (ANTS); 0 to 10 Likert scale; /40). The perceived stress level, satisfaction and the score of medical knowledge were also assessed.

Results: All anesthesia residents were randomized ( $n=48$; OT+ group, $n=37$; OT- group). At the end of the session, the global score of ANTS learning and the medical knowledge score were similar in the two groups: $31 \pm 4(\mathrm{OT}+)$ and $31 \pm 5 / 40$ (OT-) $(p=0.55)$ and $12 \pm 2(\mathrm{OT}+)$ and $12 \pm 2 / 20$ (OT-) (p=0.47). The 2 groups had a positive and similar perception of learning stress management, improvement of crisis skills management, satisfaction and changes in professional practice after the training session.

Conclusions: This study has shown a positive perception of ANTS learning after crisis training without difference between using or not an OT in anesthesia residents. More studies are necessary to define the place of this educational tool.

Trial registration: researchregistry.com. Registration number: researchregistry7055. Retrospectively registered August 13, 2021.

\section{Background}

In crisis situations, anesthesiologists must quickly and accurately mobilize technical (medical and protocol knowledge, procedural skills) and non-technical (team management, leadership...) skills. The low incidence of clinical crises does not allow traditional learning at the patient's bedside nor maintenance of competence. Simulation based education is recommended for enhance technical and non-technical skills (NTS) [1-5]. In France, the increase in the number of anesthesia residents and the limited number of instructors leads to organizational problems for simulation centers. For example, during high-fidelity simulation training scenarios, some participants are active participants and some are only observers of their colleagues. It is necessary to assess whether observers obtain the same learning outcomes than those who are role-playing in scenarios. Some studies have shown that some learnings outcomes are similar between active participants and observers [6-11] while others show a greater learning benefit when the learner is an active participant [11-14]. The benefits of observation in simulation-based medical education is increasingly recognized $[15,16]$. The social learning theory proposed by Bandura [17] and adapted to simulation states that vicarious learning occurs because from the observation of others, one can get an idea of how behaviors are produced and then reproduce them [18]. This beneficial 
effect has recently been confirmed in a meta-analysis of 13 randomized studies [16]. To reinforce the positive effects that seem nevertheless achieved in the role of observer, it has been proposed to involve observers in the scenarios through the use of an observer tool (OT) that observers must fill out as the scenario unfolds [15]. The observer tool is usually a list of key points, in a paper format to highlight the pedagogical objectives which can be technical, non-technical or mixed. In a recent literature review, $\mathrm{O}^{\prime}$ Regan et al. encourage the use of an OT [15] suggesting that it is associated with improved learning and satisfaction by making the observer more active. However, literature lacks randomized studies comparing learning outcomes of passive observers to a group of active observers who are using an OT. In a previous study [19], an OT dedicated to medical knowledge improved learning in anesthesia residents during simulation. However, it remains uncertain whether NTS learning outcomes might also be improved by using an OT.

The aim of the study was to evaluate the impact of an NTS-based OT on NTS learning of anesthesia residents using a randomized design.

\section{Methods}

\section{Study description}

This prospective and randomized controlled study was conducted at the LabForSIMS simulation center of Paris-Saclay Medical school. The aim was to evaluate the impact of an NTS-based OT on NTS learning of anesthesia residents. Approval had been obtained from the Ethical Committee for Research of the French Society of Anesthesia and Intensive Care Medicine (SFAR, IRB 00010254-2018-102). The trial has been retrospectively registered on researchregistry.com (August 13, 2021; registration number: researchregistry7055). All methods were performed in accordance with the relevant guideline and regulation. The study was carried out with the use of the CONSORT tool adapted for simulation studies[20] and the GREET Tool for educational studies[21].

Third and fourth year anesthesia residents of the Paris area were enrolled after having given their written consent (GC.A.). This high-fidelity simulation session is part of their mandatory training and apart from their refusal to participate, no exclusion criteria were used.

Each resident participated in a full day of simulation-based training composed of 6 scenarios (cardiac arrest, malignant hyperthermia, local anesthetic systemic toxicity and grade III anaphylactic shock, residual muscle relaxant, difficult intubation). Scenarios and the educational objectives were the same every day during the training week. Thus, only the role played varied during the day. For each scenario, two residents played the role of the senior anesthesiologist and of the anesthesia resident respectively. A third resident played the role of another senior anesthesiologist who could be called as a backup person. This third active participant was always involved at some time in the scenario, either being called by the participants themselves or the call was suggested by an instructor playing the role of a facilitator and this was always agreed by the participants. Participants were neither aware in advance of the role to which 
they would be assigned nor of the scenario in which they would be involved. Observers were seated in an adjacent room in which the scenario was broadcasted by live video transmission.

Each resident was active participant at least once and observer of the 5 other scenarios. After each scenario, all residents participated to a debriefing with instructors. The debriefing was carried out using the RAS method (reaction, analysis and synthesis) [22]. The actors were initially invited to give their feelings and emotions. Then the analysis phase allowed for a reflective analysis of the situation by encouraging active participants and observers to highlight the positive and negative points concerning technical and non-technical skills (defined by the educational objectives of each scenario). In addition, the residents recalled, if necessary, the concepts of technical and non-technical skills if the latter had not been used correctly during the scenario and decontextualized the situation. Finally, the synthesis made it possible to highlight the key messages of the educational objectives of each scenario.

To facilitate the organization of the day (withdrawal, change), the randomization took place just before the simulation days based on invitations scheduled over 5 days (A.B., using the random function of the Excel( software). The randomization number corresponded to the order of presence.

Anesthesia residents (Fig. 1) were randomized into two groups according to the strategy used when residents observed the simulation scenarios (not role-playing):

- OT + group: an observer tool (based on non-technical skills) was used

- OT- group: no observer tool was used

\section{Observer tool}

In the OT + group, an observer tool in paper format was distributed immediately before each scenario. The non-technical skills-based observer tool was constructed using the items of the Anaesthetists' NonTechnical Skills (ANTS) from the work of Fletcher et al[23]. Observers in the OT + group had to use this observer tool over the 5 scenarios by rating each item of the non-technical skills grid using a Likert scale (0 to 10). If the ANTS item was not relevant to the situation, then the resident wrote "not applicable"

\section{Assessment method}

The main outcome parameter was the non-technical skills learning outcomes assessed by the global score of self-assessed non-technical skills learning at the end of the training day (Kirkpatrick level 2). Assessment of learning was based on questions which used the ANTS scoring system [23] and asked the perception of the resident regarding his (her) understanding and knowledge of NTS. The ANTS scoring system uses 15 questions divided in four categories and assesses task management, teamworking, situation awareness and decision-making and uses a Likert scale ( 0 to 10 ) (global score /40). The four subcategories of the ANTS score were also compared separately as a secondary outcome. Additional questions assessing satisfaction on the formative value of the day (Kirkpatrick level 1), perception of stress, self-assessment of learning (Kirkpatrick level 2) and expected changes in future practice 
(Kirkpatrick level 1) were used. Moreover, assessment of medical knowledge (specifically dedicated to the training scenarios) was carried out by a 20 -item multiple-choice questionnaire (MCQ) which had been previously established by the investigators.

\section{Statistical analysis}

In a previous study [19] carried out in our simulation center, the average overall ANTS score, established by self-assessment was 30 points out of 40 among residents who had been at least once active participants during the simulation day.

Assuming that the use of an observer tool would increase the overall self-perceived ANTS score by 3 points on average, with an expected mean ANTS score of 29 out of 40 in the control group; using a standard deviation of 4 points, and considering alpha risk $=5 \%$ and beta risk $=20 \%$ (80\% power) with a bilateral test, 28 residents per group had to be included in each group to observe a significant difference https://biostatgv.sentiweb.fr/?module=etudes/sujets).

Results are presented as mean \pm standard deviation or percentage. The statistical analyses were carried out with the software JMP® software (Cary, NC 27513 - 2414, USA). Statistical comparisons used twotailed Student's t-test and analysis of variance for parametric and continuous variables, a Chi-square test for proportions, and a Wilcoxon test for non-parametric variables. A value of $p<0.05$ was considered significant.

\section{Results}

Inclusion

In June 2018, all 85 residents consented to participate in the training day and were randomized: $n=48$ in OT+ group and $\mathrm{n}=37$ in OT- group. Individual characteristics of the residents are described in Table 1. Each resident was an active participant at least once and observer of the 5 other scenarios.

\section{Primary outcome: ANTS learning}

At the end of the session, the global score of the self-perceived ANTS learning was $31 \pm 4$ in the OT+ group and $31 \pm 5 / 40$ in the OT- group $(p=0.55)$ (Table 2). Furthermore, no significant difference was found between the groups among the different ANTS categories or among the fifteen ANTS items analyzed separately in a secondary analysis (Table 3).

\section{Secondary outcomes}

The medical knowledge score was not significantly different between the two groups (OT+ group: $12 \pm 2$ versus OT- group $12 \pm 2 / 20)(p=0.47)$. The 2 groups had a positive and similar perception in terms of learning of stress management ( $7.4 \pm 1.6$ vs $7.1 \pm 2.2)$, improvement of crisis skills management ( $8.7 \pm$ 1.4 vs $8.8 \pm 1.3)$, satisfaction ( $9.2 \pm 1.1$ vs $9.1 \pm 1.2)$ and professional impact of the training $(8.3 \pm 1.4$ vs $8.1 \pm 1.6)$, respectively in the OT+ vs OT- groups $(p>0.05)($ Table 4$)$. 


\section{Discussion}

This study showed a positive perception in terms of NTS learning after crisis management training by high-fidelity simulation with no difference when using or not a NTS-based OT among residents who observed scenarios. No significant difference was also found in the assessment of knowledge. Likewise, a positive and similar perception was observed in terms of learning stress management, improving skills to manage a crisis, satisfaction and the professional impact of the training.

Some studies have tried to improve the learning of observers during simulation sessions using tools [8, $24,25]$. Using an observer tool is believed to allow more active learning[15]. The literature shows that active learning facilitates attention during training and improves students' performance [26]. The improved learning during active observation can be explained by the attention boost effect [27], a theory which suggests that when two actions are performed simultaneously, attention is then increased, and even more when the different elements to be observed are frequent [28]. Implementation of almost all NTS was indeed necessary in each of our crisis scenarios and using the OT could have made it possible to reinforce the learning of these items. In our study, although observers had a positive feeling in terms of NTS learning, we could not demonstrate any beneficial effect on learning these skills when using a NTSbased OT. To our knowledge, this study is the only one which randomly studied the specific impact of an observer tool on the learning of NTS. In 2012, Kaplan et al. [8] provided observers with a "critical action checklist" observation grid including a set of technical and non-technical actions to improve patient care but all observers used the observer tool and the post-test evaluation which was carried out by a questionnaire based on non-technical skills did not display any difference in the average score.

Only the study by Stegmann et al. [24] studied the impact of an observer tool in a comparative study among observers. In this study, 200 medical students were trained with a sham patient with rectal bleeding and abdominal pain. The observers used or not a checklist targeting technical skills (performing a rectal examination) and non-technical skills (patient information, doctor-patient relationship). For each skill thirteen items were defined and the observer had to judge whether they had been performed correctly or not. A significant improvement in knowledge relating to doctor-patient communication was recorded among observers equipped with the observer tool but unfortunately the study was non-randomized.

A previous work [19] randomized anesthesia residents to use an observer tool when not role-playing. The observer tools were based on crisis cognitive aids (i.e. emphasizing technical skills and medical knowledge). This study showed an increased acquisition of medical knowledge skills when using an observer tool. The acquisition of non-technical skills was also assessed using the same self-assessment than this study (secondary endpoint). As in the current study, no significant difference was shown in the acquisition of non-technical skills and absolute values were in the same range. Thus, compared to a technical-medical knowledge OT, the use of a non-technical OT under similar conditions had no effect on the learning of NTS. This could be explained by the fact that a non-technical OT seems more abstract than a technical OT. Indeed, this is an area which is not much taught in initial training as the importance of NTS in professional practice has been recognized only recently. In addition, the contribution of a non- 
technical OT as such could be less useful for learning non-technical skills because the debriefing, in which all residents participate, frequently emphasizes non-technical skills.

A greater satisfaction score is often obtained with simulation training but the value of this outcome is debated. In our study, satisfaction ratings were very high (>9/10), but not significantly different. The use of an OT therefore had no impact on satisfaction. This result agrees with our previous study in which satisfaction was similarly high in the two groups[19]. In the study by Hober [25] observing learners reported great satisfaction but in this study satisfaction was not measured objectively.

Regarding the change in professional practices, observers had a similar and very favorable perception (> $8 / 10$ ) whether or not they had used the observation grid. This result is also in agreement with our previous work [19]. This lack of significant difference could be explained by a measurement that may be done too early. Indeed, as the immediate self-assessment was being carried out at the end of the day, projection into the future is not easy and awareness of the change in professional practice may only occur after having been again exposed to a situation requiring the use of NTS.

Regarding the assessment of knowledge (level 2 according to Kirkpatrick), our study found no significant difference whether or not learners had used the observation grid. Likewise, a positive and similar perception was observed in terms of learning to manage stress and skills to manage a crisis. These results are in contradiction with those of our previous study but this can easily be explained by the fact that the technical skills were not addressed in the present study [19].

The literature regarding the use of tools to increase observer learning is limited $[8,15,24,25][19]$ and research must continue to define their pedagogical value. As shown above, the design of the studies often remains of limited quality, making interpretation still uncertain.

The strengths included the fact that our study was carried out prospectively and randomized and that we used the ANTS grid which is one of the scores which have been well validated[29]. However, it has also several limitations. One of the first limitations is the use of self-assessment. However, it would have been difficult to set up a study design in which external evaluation could have been used. Although the ANTS scoring system is well validated and widely used [29], this scale is however complex to apply even after specific training ${ }^{26}$. Another limitation is the lack of assessment of NTS before training. In order to study the impact of a measure on learning, a pre-test evaluation is the reference method. The greater the variation between the pre and post-test assessment, the more effective the action is. However, we were unable to perform a pre-test assessment and we assumed that the residents had the same level of NTS at the start as they had the same previous clinical experience. Moreover, because of monocentric study, the results weren't generalizable. Finally, our study assessed the perception of learning NTS with or without using an OT immediately after training. A remote assessment could also have been of interest to assess knowledge retention.

\section{Conclusions}


This randomized, controlled study has shown a positive perception in terms of non-technical skills learning after high-fidelity simulation training in crisis management but found no difference in most outcomes when a NTS-based OT was used or not in in anesthesia residents.

As this educational tool is believed to be useful to increase the involvement of observers during simulation sessions, additional work is necessary to clarify the place of this tool in improving learners' training.

\section{Abbreviations}

ANTS: Anaesthetists' Non-Technical Skills

NTS: non-technical skills

OT: observer tool

\section{Declarations}

Ethics approval and consent to participate

This study was approved by the Ethical Committee for Research of the French Society of Anesthesia and Intensive Care Medicine (SFAR, IRB 00010254-2018-102) (IRB 00010254-2018-102). All participants were informed and consented. All methods were performed in accordance with the relevant guideline and regulation.

Consent for publication

Not applicable

Availability of data and material

The datasets used and/or analyzed during the current study are available from the corresponding author on reasonable request.

Competing interests

The authors declare that they have no competing interests

\section{Funding}

Not applicable

Authors' contributions 
$A B$ designed the study, performed the inclusion, analyzed and interpreted the data and was a major contributor in writing the manuscript.

GCA performed the inclusion, analyzed and interpreted the data regarding and was a contributor in writing the manuscript.

PR performed the inclusion, analyzed and interpreted the data regarding

DB designed the study, analyzed and interpreted the data and was a contributor in writing the manuscript.

All authors read and approved the final manuscript

Acknowledgements

We would like to acknowledge the LabForSIMS team (B Bech and A Renault) and all the instructors ( $M$ Bruyère, D Fletcher, K Bouattour, B Jeannin, V Jouffroy, A Le Gouez, M Binczak, C Vermersch, A Rosa, N Essafi, S Figueiredo, P Trouiller, Y Bornemann, S Grousson, M Le Guen).

\section{References}

1. L'Her E, Geeraerts T, Desclefs JP, Benhamou D, Blanie A, Cerf C, Delmas V, Jourdain M, Lecomte F, Ouanes I et al: Simulation-based teaching in critical care, anaesthesia and emergency medicine. Anaesth Crit Care Pain Med 2020, 39(2):311-326.

2. Yee B, Naik VN, Joo HS, Savoldelli GL, Chung DY, Houston PL, Karatzoglou BJ, Hamstra SJ: Nontechnical skills in anesthesia crisis management with repeated exposure to simulation-based education. Anesthesiology 2005, 103(2):241-248.

3. Cook DA, Hatala R, Brydges R, Zendejas B, Szostek JH, Wang AT, Erwin PJ, Hamstra SJ: Technologyenhanced simulation for health professions education: a systematic review and meta-analysis. JAMA 2011, 306(9):978-988.

4. Bruppacher HR, Alam SK, LeBlanc VR, Latter D, Naik VN, Savoldelli GL, Mazer CD, Kurrek MM, Joo HS: Simulation-based training improves physicians' performance in patient care in high-stakes clinical setting of cardiac surgery. Anesthesiology 2010, 112(4):985-992.

5. Park CS, Rochlen LR, Yaghmour E, Higgins N, Bauchat JR, Wojciechowski KG, Sullivan JT, McCarthy RJ: Acquisition of critical intraoperative event management skills in novice anesthesiology residents by using high-fidelity simulation-based training. Anesthesiology 2010, 112(1):202-211.

6. Lai A, Haligua A, Dylan Bould M, Everett T, Gale M, Pigford AA, Boet S: Learning crisis resource management: Practicing versus an observational role in simulation training - a randomized controlled trial. Anaesth Crit Care Pain Med 2016, 35(4):275-281. 
7. Thidemann IJ, Soderhamn O: High-fidelity simulation among bachelor students in simulation groups and use of different roles. Nurse Educ Today 2013, 33(12):1599-1604.

8. Kaplan BG, Abraham C, Gary R: Effects of participation vs. observation of a simulation experience on testing outcomes: implications for logistical planning for a school of nursing. Int $\mathrm{J}$ Nurs Educ Scholarsh 2012, 9:Article 14.

9. Blanie A, Roulleau P, Mengelle C, Benhamou D: Comparison of learning outcomes between learning roles (spectator and actor) during an immersive simulation. Anaesth Crit Care Pain Med 2017, 36(4):243-244.

10. Bong CL, Lee S, Ng ASB, Allen JC, Lim EHL, Vidyarthi A: The effects of active (hot-seat) versus observer roles during simulation-based training on stress levels and non-technical performance: a randomized trial. Adv Simul (Lond) 2017, 2:7.

11. Ying Y, Yacob M, Khambati H, Seabrook C, Gerridzen L: Does being in the hot seat matter? Effect of passive vs active learning in surgical simulation. Am J Surg 2020, 220(3):593-596.

12. Stiefel F, Bourquin C, Layat C, Vadot S, Bonvin R, Berney A: Medical students' skills and needs for training in breaking bad news. J Cancer Educ 2013, 28(1):187-191.

13. Reime MH, Johnsgaard T, Kvam Fl, Aarflot M, Engeberg JM, Breivik M, Brattebo G: Learning by viewing versus learning by doing: A comparative study of observer and participant experiences during an interprofessional simulation training. J Interprof Care 2017, 31(1):51-58.

14. Blanie A, Gorse S, Roulleau P, Figueiredo S, Benhamou D: Impact of learners' role (active participantobserver or observer only) on learning outcomes during high-fidelity simulation sessions in anaesthesia: A single center, prospective and randomised study. Anaesth Crit Care Pain Med 2018, 37(5):417-422.

15. O'Regan S, Molloy E, Watterson L, Nestel D: Observer roles that optimise learning in healthcare simulation education: a systematic review. Adv Simul (Lond) 2016, 1:4.

16. Delisle M, Ward MAR, Pradarelli JC, Panda N, Howard JD, Hannenberg AA: Comparing the Learning Effectiveness of Healthcare Simulation in the Observer Versus Active Role: Systematic Review and Meta-Analysis. Simul Healthc 2019, 14(5):318-332.

17. Horsburgh J, Ippolito K: A skill to be worked at: using social learning theory to explore the process of learning from role models in clinical settings. BMC Med Educ 2018, 18(1):156.

18. Bethards M: Applying Social Learning Theory to the Observer Role in Simulation. Clinical Simulation in Nursing 2014, 10:e65-e69.

19. Suet G, Blanie A, De Montblanc J, Benhamou D: Use of an Observer Tool to Enhance Observers' Learning of Anesthesia Residents During High-Fidelity Simulation: A Randomized Controlled Trial. Simul Healthc 2021.

20. Cheng A, Kessler D, Mackinnon R, Chang TP, Nadkarni VM, Hunt EA, Duval-Arnould J, Lin Y, Cook DA, Pusic M et al: Reporting Guidelines for Health Care Simulation Research: Extensions to the CONSORT and STROBE Statements. Simul Healthc 2016, 11(4):238-248. 
21. Phillips AC, Lewis LK, McEvoy MP, Galipeau J, Glasziou P, Moher D, Tilson JK, Williams MT: Development and validation of the guideline for reporting evidence-based practice educational interventions and teaching (GREET). BMC Med Educ 2016, 16(1):237.

22. Fanning RM, Gaba DM: The role of debriefing in simulation-based learning. Simul Healthc 2007, 2(2):115-125.

23. Fletcher G, Flin R, McGeorge P, Glavin R, Maran N, Patey R: Anaesthetists' Non-Technical Skills (ANTS): evaluation of a behavioural marker system. $\mathrm{Br} J$ Anaesth 2003, 90(5):580-588.

24. Stegmann K, Pilz F, Siebeck M, Fischer F: Vicarious learning during simulations: is it more effective than hands-on training? Med Educ 2012, 46(10):1001-1008.

25. Hober CL: Student Perceptions of the Observer Role Play Experiences in the Implementation of a High Fidelity Patient Simulation in Bachelor's Degree Nursing Programs. 2012.

26. Freeman S, Eddy SL, McDonough M, Smith MK, Okoroafor N, Jordt H, Wenderoth MP: Active learning increases student performance in science, engineering, and mathematics. Proc Natl Acad Sci U S A 2014, 111(23):8410-8415.

27. Swallow KM, Jiang YV: The attentional boost effect really is a boost: evidence from a new baseline. Atten Percept Psychophys 2014, 76(5):1298-1307.

28. Swallow KM, Makovski T, Jiang YV: Selection of events in time enhances activity throughout early visual cortex. J Neurophysiol 2012, 108(12):3239-3252.

29. von Wendt CEA, Niemi-Murola L: Simulation in Interprofessional Clinical Education: Exploring Validated Nontechnical Skills Measurement Tools. Simul Healthc 2018, 13(2):131-138.

\section{Tables}

Table 1 : Characteristics of anesthesia residents. Results are presented as mean \pm standard deviation or number (percentage). A value of $p<0.05$ was considered significant.

*1 missing data for age and 3 missing data for simulation experience. 


\begin{tabular}{|llll|}
\hline & $\begin{array}{l}\text { OT+ group } \\
(\mathbf{n = 4 8 )}\end{array}$ & OT- group (n=37) & $\boldsymbol{p}$ \\
\hline Age* (years \pm SD) & $27.1 \pm 1.2$ & $27.2 \pm 1.2$ & 0.74 \\
\hline 6-month training rotations $(\mathrm{n} \pm \mathrm{SD})$ & $6 \pm 0,27$ & $6 \pm 0$ & 0.32 \\
\hline Male $(\mathrm{n}, \%)$ & $27(57 \%)$ & $21(57 \%)$ & 0.44 \\
\hline Simulation-based training experience * $(\mathrm{n}, \%)$ & & & 0.27 \\
\hline$<3$ training sessions & $15(32 \%)$ & $17(46 \%)$ & \\
\hline [3-5] training sessions & $28(60 \%)$ & $15(41 \%)$ & \\
\hline$>5$ training sessions & $3(6 \%)$ & $3(8 \%)$ & \\
\hline
\end{tabular}

Table 2 : Perception of NTS learning between the two groups and comparison of different ANTS categories at the end of the session. Results are presented as mean \pm standard deviation. A value of $p<$ 0.05 was considered significant.

\begin{tabular}{|llll|}
\hline $\begin{array}{l}\text { Perception of NTS learning } \\
\text { (Likert scale } 0 \text { - 10) }\end{array}$ & $\begin{array}{l}\text { OT+ group } \\
(\mathbf{n = 4 8 )}\end{array}$ & $\begin{array}{l}\text { OT- group } \\
(\mathbf{n}=\mathbf{3 7})\end{array}$ & $\boldsymbol{p}$ \\
\hline Global ANTS Score $(\mathbf{4 0 )}$ & $30.5 \pm 4.2$ & $31.0 \pm 4.5$ & 0.55 \\
\hline Task management score (/10) & $7.9 \pm 1.1$ & $8.1 \pm 1.1$ & 0.32 \\
\hline Teamwork score $(/$ 10) & $7.4 \pm 1.4$ & $7.5 \pm 1.3$ & 0.63 \\
\hline Situation awareness $(/ 10)$ & $7.8 \pm 1.1$ & $7.7 \pm 1.3$ & 0.81 \\
\hline Decision-making score $(/ 10)$ & $7.4 \pm 1.4$ & $7.6 \pm 1.5$ & 0.41 \\
\hline
\end{tabular}

Table 3 : Comparison of different ANTS items at the end of the session. Results are presented as mean \pm standard deviation. A value of $p<0.05$ was considered significant 


\begin{tabular}{|c|c|c|c|c|}
\hline \multicolumn{2}{|c|}{ ANTS items (Likert scale 0 - 10) } & \multirow{2}{*}{$\begin{array}{l}\begin{array}{l}\text { OT+ } \\
\text { group }\end{array} \\
(n=48) \\
7.6 \pm 1.3\end{array}$} & \multirow{2}{*}{$\begin{array}{l}\text { OT- group } \\
(n=37) \\
7.7 \pm 1.3\end{array}$} & \multirow{2}{*}{$\begin{array}{l}p \\
\\
0.66\end{array}$} \\
\hline Task management & Planning and preparing & & & \\
\hline & Prioritizing & $7.8 \pm 1.2$ & $7.6 \pm 1.5$ & 0.49 \\
\hline & Providing and maintaining standards & $8,5 \pm 1,2$ & $8,8 \pm 1,2$ & 0.18 \\
\hline & Identifying and utilizing resources & $7.9 \pm 1.5$ & $8.4 \pm 1.3$ & 0.09 \\
\hline \multirow[t]{5}{*}{ Teamwork } & $\begin{array}{l}\text { Co-ordinating activities with team } \\
\text { members }\end{array}$ & $7.9 \pm 1,6$ & $8 \pm 1.4$ & 0.78 \\
\hline & Exchanging informations & $8.2 \pm 1.6$ & $8.3 \pm 1.3$ & 0.69 \\
\hline & Using authorities and assertiveness & $6.8 \pm 1.9$ & $7 \pm 1.7$ & 0.72 \\
\hline & Assessing capabilities & $6.6 \pm 1.7$ & $6.8 \pm 2.1$ & 0.67 \\
\hline & Supporting others & $7.1 \pm 1.6$ & $7.3 \pm 1.7$ & 0.69 \\
\hline \multirow{3}{*}{$\begin{array}{l}\text { Situation } \\
\text { awareness }\end{array}$} & Gathering informations & $7.9 \pm 1.3$ & $7.7 \pm 1.6$ & 0.56 \\
\hline & Recognizing and understanding & $7.6 \pm 1.2$ & $7.9 \pm 1.5$ & 0.47 \\
\hline & Anticipating & $7.9 \pm 1.3$ & $7.6 \pm 1.6$ & 0.50 \\
\hline \multirow[t]{3}{*}{ Decision-making } & Identifying options & $7.7 \pm 1.6$ & $7.5 \pm 1.6$ & 0.71 \\
\hline & Balancing risks and selecting options & $6.8 \pm 1.8$ & $7.5 \pm 1.8$ & 0.10 \\
\hline & Re-evaluating & $7.7 \pm 1.4$ & $7.9 \pm 1.7$ & 0.42 \\
\hline
\end{tabular}

Table 4 : Comparison of perception in terms of learning of stress management, improvement of crisis management skills, satisfaction and professional impact of the training in the OT + vs OT-groups at the end of the session. Results are presented as mean \pm standard deviation. A value of $p<0.05$ was considered significant.

\begin{tabular}{|llll|}
\hline Self-assessment & $\begin{array}{l}\text { OT+ group } \\
(\mathrm{n}=48)\end{array}$ & $\begin{array}{l}\text { OT- group } \\
(\mathrm{n}=37)\end{array}$ & $\boldsymbol{p}$ \\
\hline Likert scale 0 - 10) & $7.4 \pm 1.6$ & $7.1 \pm 2.2$ & 0.57 \\
\hline Improvement of crisis management skills & $8.7 \pm 1.4$ & $8.8 \pm 1.3$ & 0.91 \\
\hline Satisfaction with formative value & $9.2 \pm 1.1$ & $9.1 \pm 1.2$ & 0.66 \\
\hline Professional impact of the training & $8.3 \pm 1.4$ & $8.1 \pm 1.6$ & 0.58 \\
\hline
\end{tabular}


Figures

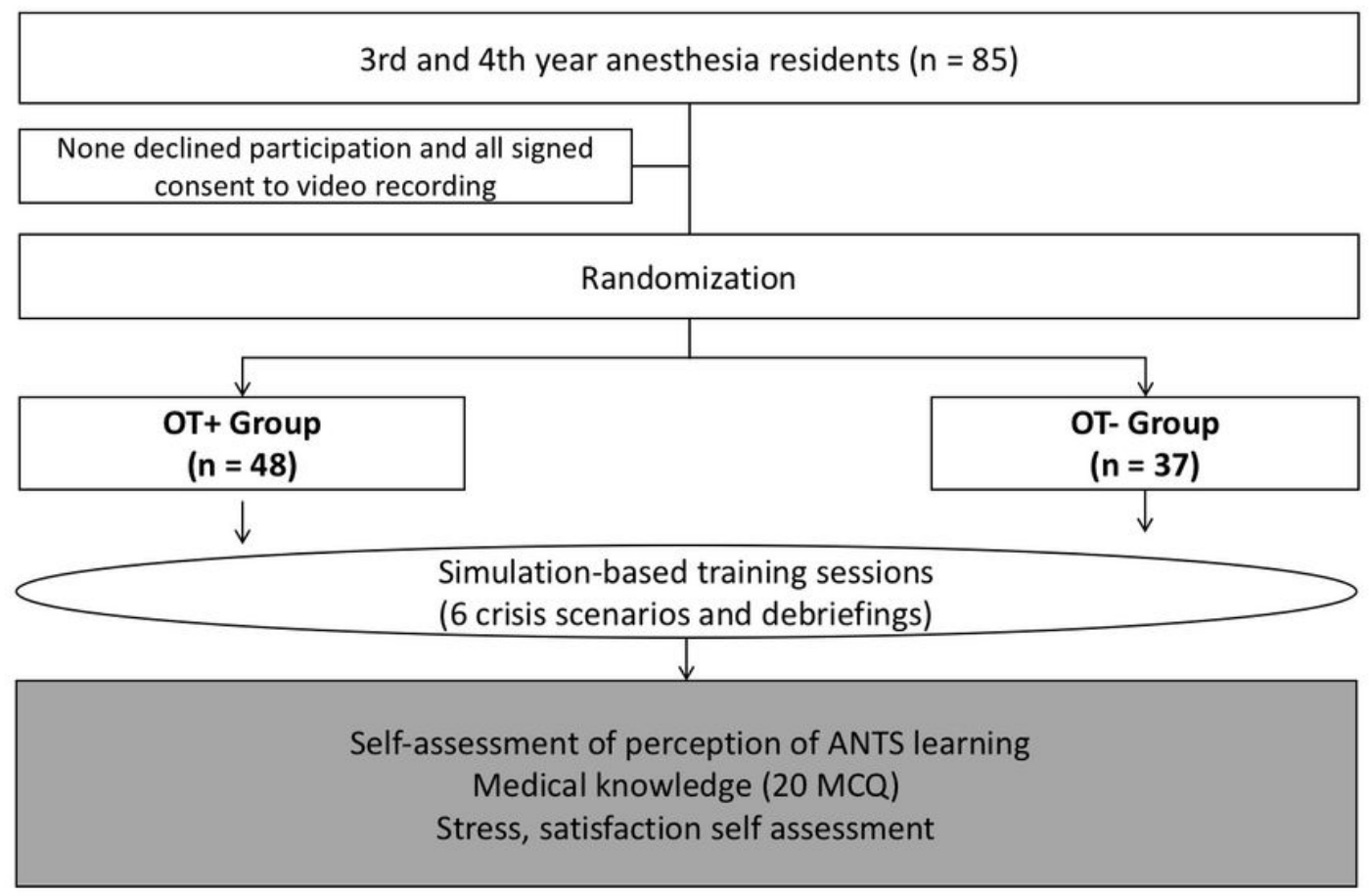

\section{Figure 1}

Study flow chart 